\title{
Tools for Analysing Military Tactics based on Bézier Surface Pattern Recognition
}

\author{
SORMUNEN, Jari ${ }^{1}$, ESKELINEN, Harri ${ }^{2}$
}

\begin{abstract}
There are many factors which affect a military unit's success in a battle exercise. Some of these factors could be regarded as tactical and others as human factors. Some of them can be measured with numerical values while others are difficult to quantify. Nevertheless, they all affect the success of the battle exercise. This paper describes how to develop and utilize a method based on Bézier surface pattern recognition, which could be used for the overall military tactical analysis of a company's attack. This paper also explains how this method could be applied to an integrated analysis of the most important tactical factors affecting the success and task fulfilment of an attack together with the leader's decision-making and his or her tactical solutions.
\end{abstract}

Keywords: Military tactics, decision-making, company, attack exercise, Bézier

surface.

\section{Background and Introduction}

The basic tactical research, "The Success Factors of an Infantry Company's Attack" (SCAresearch), which was carried out in the Finnish Defence Forces (FDF) during the years 2004-2007 forms the empirical background of this paper. The SCA-research focused on analyzing different individual effects of selected measured explanatory variables. The vari- ables were selected from the areas of tactics, situational awareness, battle task load, human factors, background factors and response variables. During this research, 59 attack exercises by infantry companies were analyzed. Detailed results are documented in Sormunen's and Eskelinen's paper. (2010)

This paper presents a comprehensive evaluation method for tactical analysis. The devel- opment of the method started from constructing the data collection matrix. This $5 \times 4$ matrix is constructed in a simple way by displaying the general tactical elements (FDF, 2008) as columns and the known tactical principles (FDF, 2008) as rows. In this paper, the checkers which are formed at the crossings of these rows and columns of the $5 \times 4$ matrix are called central tactical variables (CTV), and the aspects they can be divided into are called tactical items. In this paper, we justify and describe this matrix construction and explain the contents of the CTVs and the tactical items. To simplify this presentation, we use the name CMEP- matrix (Command and Control, Manoeuvre, Effect, Performance Maintenance) for this $5 \times 4$

1 Lieutenant colonel, National Defence University, Finnish Defence Forces, Department of Tactics and Operations Art,00861 Helsinki, Finland

2 D.Sc., Lappeenranta University of Technology, Faculty of Technology, P.O.Box 20, 53851 Lappeenranta, Finland, email: harri.eskelinen@lut.fi

SORMUNEN, Jari, ESKELINEN, Harri: Tools for Analysing Military Tactics...

matrix and the method which uses the CMEP-matrix for data collection and tactical analysis is entitled the CMEPmethod. The CMEP-matrix is presented in Fig. 1. The set of twenty CTVs here are only an example of the components which were recognized in attack exercises during the background research. (Sormunen, Eskelinen, 2010) The CTVs and the tactical items should be adjusted depending on the battle type and the battle task. 


\begin{tabular}{|c|c|c|c|c|}
\hline $\begin{array}{l}\text { TACTICAL } \\
\text { ELEMENTS/ } \\
\text { PRINCIPLES }\end{array}$ & $\begin{array}{l}\text { COMMAND AND } \\
\text { CONTROL }\end{array}$ & MANOEUVRE & EFFECT & $\begin{array}{l}\text { PERFORMANCE } \\
\text { MAINTENANCE }\end{array}$ \\
\hline $\begin{array}{l}\text { KNOWLEDGE } \\
\text { OF } \\
\text { ADVERSARY } \\
\text { AND } \\
\text { OWN }\end{array}$ & $\begin{array}{l}\text { 1 FREEDOM OF ACTION } \\
\text { Shaping the threat } \\
\text { Possibilities of achieving effect } \\
\text { Common tactical understanding } \\
\text { Position and condition info } \\
\text { Avoiding force binding }\end{array}$ & $\begin{array}{l}2 \text { IERRAIN AND } \\
\text { CIRCUMST ANCES } \\
\text { Restrictions of adversary } \\
\text { Own force strengths } \\
\text { Dominant terrains } \\
\text { Relative agility }\end{array}$ & $\begin{array}{l}3 \text { USE OF PERFORMANCE } \\
\text { Choosing the right objecttarget } \\
\text { Avoiding passive formality } \\
\text { Active use of deceptive actions } \\
\text { Economic use of force } \\
\text { Profitable synchronization }\end{array}$ & $\begin{array}{l}4 \text { CONCEALMENT } \\
\text { Variation of action styles } \\
\text { Own battle plan secrecy } \\
\text { Situation picture of adversary } \\
\text { Effect-based decentralization }\end{array}$ \\
\hline ACTIVENESS & $\begin{array}{l}5 \text { SITUATION EVALUATION } \\
\text { AND POSSIBILITIES } \\
\text { Seeing the possibility } \\
\text { Courage to utilize } \\
\text { Will to take initiative } \\
\text { Reconnaissance-pull } \\
\text { Sensibility of thinking }\end{array}$ & $\begin{array}{l}\text { 6 BA ITLE READINESS } \\
\text { Adaptation to situations } \\
\text { Responding to the unexpected } \\
\text { Continuity of movement } \\
\text { Leadability } \\
\text { Positioning }\end{array}$ & $\begin{array}{l}7 \text { COMBAT IECHNIQUES } \\
\text { Firing situations (opening fire) } \\
\text { Adversary on move when fired } \\
\text { Own units positioned when firing } \\
\text { Active use of battle composition } \\
\text { Proper utilization of strengths }\end{array}$ & $\begin{array}{l}\text { 8 FORCE PROTECTION } \\
\text { Keeping up preparednesS } \\
\text { Ensuring early warnings } \\
\text { Own performance capacity } \\
\text { Terrain adaptation } \\
\text { Air protection and - defence }\end{array}$ \\
\hline SIMPLICITY & $\begin{array}{l}9 \text { CONCENTRATING ON THE } \\
\text { ESSENTIAL } \\
\text { Main attention on adversary } \\
\text { Battle task clear in mind } \\
\text { Action competence (training) } \\
\text { Utilization of own example } \\
\text { Short communication (signals) }\end{array}$ & $\begin{array}{l}\text { 10 EXECUTION CAPABILITY } \\
\text { Effect and speed (queues) } \\
\text { Standardized starts (STP) } \\
\text { Weapons quickly to positions } \\
\text { Aim to concentrate effect } \\
\text { Mobility improvement }\end{array}$ & $\begin{array}{l}\text { 11 CLEAR INTENTION } \\
\text { Fulfilling the battle task } \\
\text { Maximizing casualty production } \\
\text { Minimizing own force casualties } \\
\text { Satisfactory input-output ratio } \\
\text { Battle task tactics }\end{array}$ & $\begin{array}{l}\text { 12 FLEXIBILITY } \\
\text { Broad method spectrum } \\
\text { Fast adaptability } \\
\text { Speed of situation variation } \\
\text { Security }\end{array}$ \\
\hline $\begin{array}{l}\text { CONCEN- } \\
\text { TRATION } \\
\text { OF } \\
\text { EFFECT }\end{array}$ & $\begin{array}{l}\text { 13 BREAKING THE BATTLE } \\
\text { PLAN OF ADVERSARY } \\
\text { Stopping the manoeuvre } \\
\text { Forcing adversary to react } \\
\text { Aiming at surprise } \\
\text { Active choice of time and place }\end{array}$ & $\begin{array}{l}14 \text { BAT TLE PULL } \\
\text { Advantageous positions } \\
\text { Several effect directions } \\
\text { Adjusting the movement } \\
\text { Profitable battle formations } \\
\text { Situational speed }\end{array}$ & $\begin{array}{l}\text { 15 BAT TLE SUPPORT } \\
\text { Producing enough casualties } \\
\text { Overall profitable use of all fires } \\
\text { Proper centre of gravity } \\
\text { Co-effect of supporting branches } \\
\text { Breaking adversary's cohesion }\end{array}$ & \begin{tabular}{|l} 
16 BAT TLE SERMCE \\
Material readiness \\
Support to acting readiness \\
Foreseeing needs \\
Advanced fulfilment of needs \\
Pushing principle in service
\end{tabular} \\
\hline $\begin{array}{l}\text { RESERVE } \\
\text { AND } \\
\text { EXERTION } \\
\text { OF IT }\end{array}$ & $\begin{array}{l}17 \text { PREPARING FOR } \\
\text { VARIA TION OF SIIUA IION } \\
\text { Readiness for the unexpected } \\
\text { Active use of situation picture } \\
\text { Evaluating options } \\
\text { Searching culmination } \\
\text { Effort to take initiative }\end{array}$ & \begin{tabular}{l|}
18 CON TINUITY \\
Keeping up initiative \\
Aiming at battle culmination \\
Attention to possibilities \\
Focus after battle engagement \\
Keeping up battle engagement
\end{tabular} & $\begin{array}{l}19 \text { UTILIZATION OF SUCCESS } \\
\text { Developing initiative } \\
\text { Creating culmination } \\
\text { Keeping up adversary's pressure } \\
\text { Using the possibility windows } \\
\text { Perseverance }\end{array}$ & \begin{tabular}{|l} 
20 RELEASING NEW \\
RESERVE \\
Utilization of initiative \\
Utilization of culmination \\
Possibilities of continuing \\
Developing battle situations \\
Adversary's pressure growth
\end{tabular} \\
\hline
\end{tabular}

Figure 1.

The CMEP-matrix. The set of twenty CTVs is valid for analyzed infantry company's attack exercises.

\section{Qualitative Methods and Analysis}

The CMEP-matrix construction is built step by step as illustrated in Fig. 2. The rows and columns are established based on literature research. The central tactical variables and the tactical items are recognized based on the qualitative analysis of reports written by the data collectors during the SCA-research. These reports described the tactical actions of the fight- ing units in 59 attack exercises.

SORMUNEN, Jari, ESKELINEN, Harri: Tools for Analysing Military Tactics...

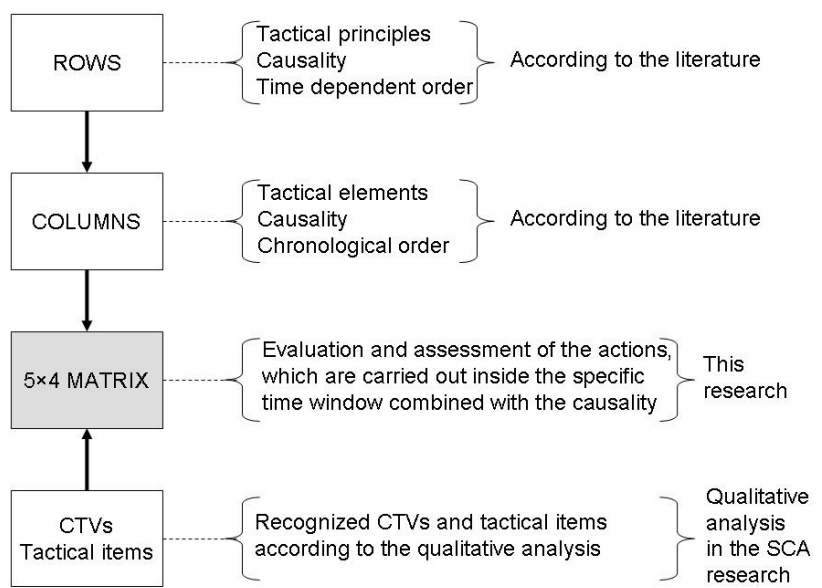

182

Figure 2.

AARMS (12) 2 (2013)

The development steps and justification of the CMEP-matrix

\section{Tactical principles and tactical elements}

First, let us discuss the justification of the rows and columns. The construction and order of the rows and the columns of the CMEP-matrix are based on the observations collected in the SCA-research (Sormunen, Eskelinen, 2010), and supported by literature research.

In the Finnish Defence Forces' Field Manual 2008 (FDF, 2008), the central tactical prin- ciples are described with the words, "consciously, actively, simply, concentratedly and con- tinuously". The sequence of the tactical principles, which is the sequence of the rows in the CMEP-matrix, is determined based on the causalities found from the literature and the qualitative analysis of the source data collected from the SCA-research. According to the Field 
Manual (FDF, 2008), tactical principles should also always be integrated with the time dependent result. Based on these facts, the sequence of the rows in the CMEP-matrix should be "knowledge of adversary and own, activeness, simplicity, concentration of effect, reserve and exertion of it". Fig. 3 illustrates the systematic search for causalities from relevant liter- ature between the tactical principles.

SORMUNEN, Jari, ESKELINEN, Harri: Tools for Analysing Military Tactics...

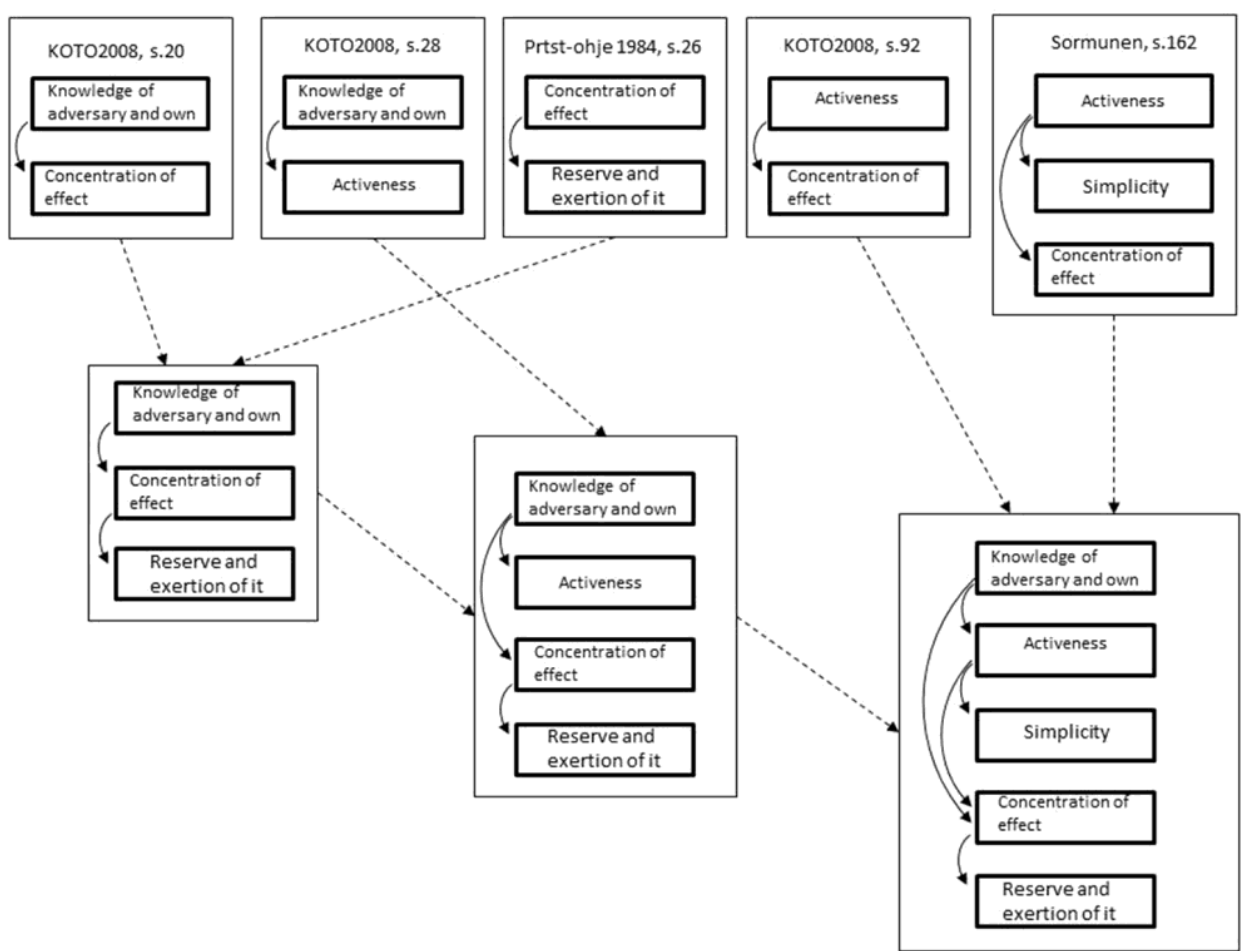

Figure 3. Systematic search for the causalities between the tactical principles.

The referenced data sources are: (FDF, 2008), (FDF, 1984) and (Sormunen, Eskelinen, 2010).

It is an interesting detail that the percentages of observations which were collected from the background research (Sormunen, Eskelinen, 2010) by utilizing qualitative analysis place the tactical principles in the same sequence as the previous literature research. The results are illustrated in Fig. 4.



AARMS (12) 2 (2013)

Figure 4. The percentages of observations dealing with tactical principles related to the

sequence of rows

183

in the CMEP-matrix. (Sormunen, Eskelinen, 2010)

AARMS (12) 2 (2013)

SORMUNEN, Jari, ESKELINEN, Harri: Tools for Analysing Military Tactics...

According to the Field Manual (FDF, 2008), the tactical elements are command and con- trol, manoeuvre, effect and performance maintenance. The tactical principles become appar- ent in the interaction with the tactical elements of the battle. According to this Field Manual, the purpose of the manoeuvre near the adversary is to move one's own troops safely to the position from which it is possible to affect the adversary effectively with fire. Further, com- mand and control can be seen as a factor which aims to integrate the other tactical elements of the battlefield. When considering the chronological order of the tactical elements, the sequence is command and control, manoeuvre, effect and 
performance maintenance. The tactical elements (columns of the CMEP-matrix) of the CMEP-matrix are the same as the tactical elements in the battlefield according to the Field Manual. (FDF, 2008)

The tactical elements presented in the columns of the CMEP-matrix can be evaluated by utilizing the words presented in the rows of the CMEP-matrix (consciously, actively, simply, concentrated and continuously). For example, command and control could simultaneously be conscious, active, simple, concentrated and/or continuous). This viewpoint has led to the $5 \times 4$

CMEP-matrix and enables the qualitative tactical evaluation of an attack.

The analyzed reports written by the data collectors of the SCA-research (Sormunen, Es- kelinen, 2010) included 84 perceptions which directly discussed measured absolute time intervals, the registered relative quickness of the effect or the right timing in different tactical actions in the battle space. Based on these observations, it was possible to define the critical time interval, the so-called time window (twn) in which certain actions in the battle space should be carried out. This time window also describes the time limits within which one's own forces should react to reach higher tactical speed than the adversary. Some examples of different types of perceptions (Sormunen, Eskelinen, 2010) dealing with time are presented in Table 1. This information is derived to establish the size of the critical time window. Also based on the background research (Sormunen, Eskelinen, 2010), some alternative ways to describe the utilization levels of the opened time window are presented in Table 2.

Table 1. Examples of different types of perceptions dealing with time. (Sormunen, Eskelinen, 2010)

\begin{tabular}{|l|l|}
\hline Type of perception & Perception (example) \\
\hline $\begin{array}{l}\text { Required or used absolute time } \\
\text { for certain actions. }\end{array}$ & $\begin{array}{l}\text { "For example, the best result was five minutes, which } \\
\text { was required from the point when the vehicles arrived to } \\
\text { the footing area to the point when the platoon started to } \\
\text { progress the attack." }\end{array}$ \\
\hline $\begin{array}{l}\text { Tactical speed comparison be- } \\
\text { tween two fighting sides. }\end{array}$ & $\begin{array}{l}\text { "The unit which was moving more quickly had the edge } \\
\text { in capturing the advantageous positions in the terrain } \\
\text { of the battlefield." }\end{array}$ \\
\hline $\begin{array}{l}\text { Estimation or evaluation of the } \\
\text { length of the time interval of an } \\
\text { action or between two actions. }\end{array}$ & \begin{tabular}{l} 
"Too much time was spent after the battle to turn the right direction for the next departure." \\
\hline
\end{tabular}
\end{tabular}

SORMUNEN, Jari, ESKELINEN, Harri: Tools for Analysing Military Tactics...

Table 2. Examples of different ways to describe the utilization levels of the time window in the analyzed attacks. (Sormunen, Eskelinen, 2010)

\begin{tabular}{|l|l|}
\hline Type of perception & Perception (example) \\
\hline $\begin{array}{l}\text { An open (optional) time } \\
\text { window is recognized. }\end{array}$ & $\begin{array}{l}\text { "Often the key factor is the higher speed compared to the } \\
\text { adversary. The winner of the battle is often the soldier of the } \\
\text { unit which is faster and acts better according to the require- } \\
\text { ments of the battle situation." }\end{array}$ \\
\hline $\begin{array}{l}\text { The open time window is } \\
\text { utilized. }\end{array}$ & $\begin{array}{l}\text { "The fighting side which has grasped the initiative has the } \\
\text { edge over the adversary at the beginning of the battle. After } \\
\text { this, the quick defeat of the adversary is ensured by a quick } \\
\text { creation of the center of gravity." }\end{array}$ \\
\hline $\begin{array}{l}\text { The open time window is } \\
\text { wasted. }\end{array}$ & $\begin{array}{l}\text { "In this case, the prepared attack is, firstly, too slow and vul- } \\
\text { nerable, and secondly, it may be directed, due to its slow- } \\
\text { ness, not towards the regiment headquarters but in front of } \\
\text { the adversary's second firing level. This turns the role of the } \\
\text { attacker to the role of the target at the flank." } \\
\text { but it is not utilized. }\end{array}$ \\
\hline
\end{tabular}

From the viewpoint of the CMEP-method, two of the time windows are more interest- ing than the rest. The first time window covers the time used for deciding and ordering the intended tactical actions. The second time window covers the time used for performing the intended and ordered actions and additional technical delays to the impact moment of the main weapon effect. It is therefore justified to evaluate how the CMEP-method works with different types of time windows.

From the tactical viewpoint, the central aspect which connects the rows and columns of the CMEP-matrix is time. As illustrated in Fig. 5, the time dependent structure of the CMEP- matrix makes it possible to study in the desired time 
window both what tactical actions have been taken and in what way these actions were carried out.

Within the CMEP-matrix, a part of a tactical phenomenon could be expressed as "con- scious command and control" in the time window "tw1" or it could be entitled "active ma- noeuvre" in the time window "tw2" if it is relevant to limit the size of the time window to illustrate just a small part of the tactical phenomenon. From the viewpoint of the battle result, the study of tactical phenomena could be extended in the time window "tw3", which covers several checkers of the CMEP-matrix (several tactical actions have taken place and are car- ried out in different ways). Because both the tactical elements and tactical principles are time dependent and there is causality which establishes their sequence, there is also a time axis passing along the diagonal of the CMEP-matrix.

The CMEP-matrix construction makes it possible to describe the tactical grounds so that e.g. good command and control could be simultaneously based on situational awareness (consciousness) and activeness, or on the other hand, the effect could be simultaneously concentrated and simple. In addition to the description of these types of separate tactical

SORMUNEN, Jari, ESKELINEN, Harri: Tools for Analysing Military Tactics...

reason-consequence-relations, the CMEP-matrix construction makes it possible to study comprehensively different integrated tactical phenomena within the $5 \times 4$ field (see Fig. 2).

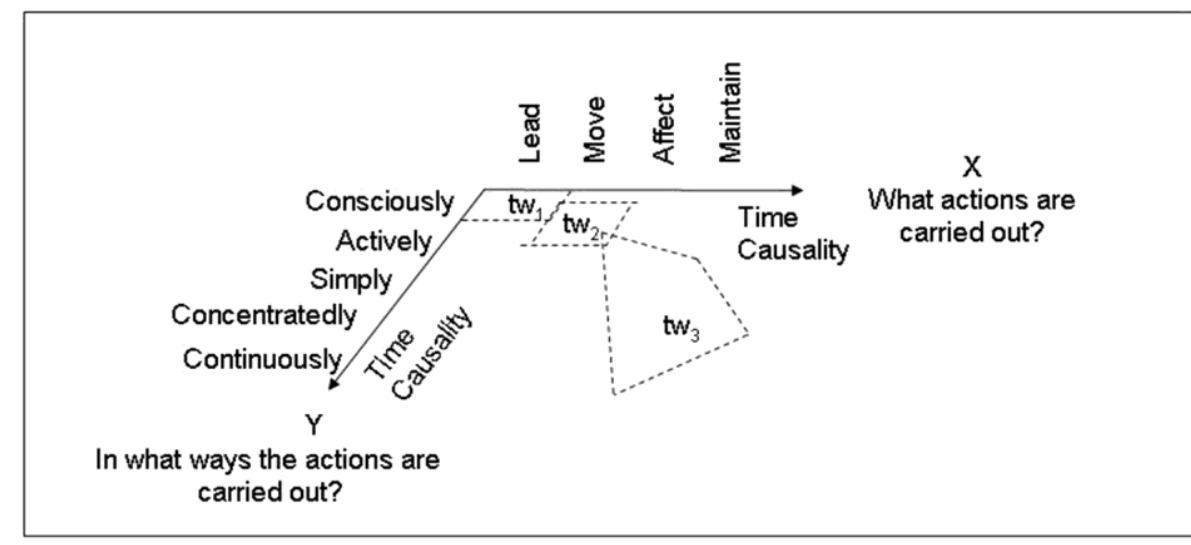

$\mathrm{tw}_{1}=$ time window 1

$\mathrm{tw}_{2}=$ time window 2

$\mathrm{tw}_{3}=$ time window 3

Figure 5. Utilization of the matrix construction for forming the tactical time windows.

\section{Central tactical variables and tactical items}

Let us then discuss the establishment of central tactical variables and tactical items. For this qualitative analysis, the source data collected from the background research included 12000 observations (written comments) by data collectors. This qualitative analysis process reduces and compresses the initial source data so that the total amount of 12,000 observations is re- duced to 500-600 observations at each crossing of CMEP-matrix rows and columns. The reclassification stage of the remaining observations compresses the amount to 80-100. Finally, after the abstraction stage of the qualitative analysis roughly 20-25 descriptions were found to describe the crossing of each row and column of the CMEP-matrix. After the generaliza- tion of these descriptions to fit in the framework of this research, four to five tactical items were found at each crossing of rows and columns. Finally, these items could be described with one term, which was then assigned as the name of the corresponding central tactical variable. This data reduction and compressing process is described in Fig. 6 according to Miles's and Huberman's book. (Miles, Huberman, 1994)

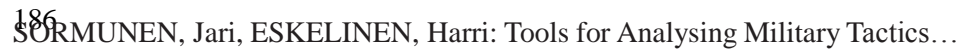
AARMS (12) 2 (2013) 


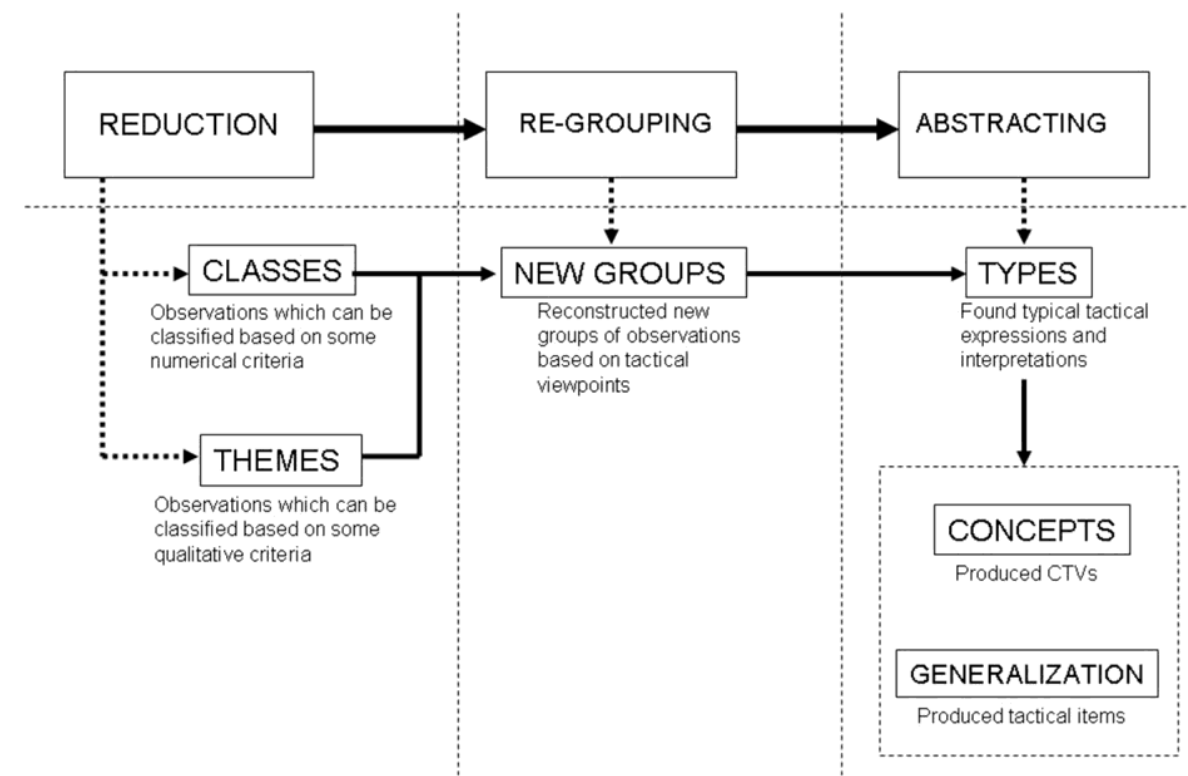

Figure 6. The establishment of the content of central tactical variables and the tactical items based on the principle of qualitative analysis in Miles's and Huberman's book (1994).

The qualitative analysis is carried out at each crossing of the tactical elements and the tactical principles of the CMEP-matrix. In this brief article, it is of course difficult to show all 12,000 observations and their interpretations, but the principle which leads to the defini- tions of CTVs and tactical items follows the routine presented in Fig. 6. In addition, when referring back to Fig. 1, we notice from the literature that for example Liddell, Hart and Lind have emphasized such comparable contents as "Freedom of action" and "Clear intention" (Liddell, 1954); (Lind, 1985) and Bellamy (1990) has emphasized such comparable contents as "Terrain and circumstances", "Use of performance", "Battle readiness", "Concentrating on the essential", "Execution capability", "Flexibility", "Battle pull", "Battle support" and "Releasing new reserve". (Bellamy, 1990) These findings support the results of the qualita- tive analysis in this research.

\section{Quantitative Methods and Analysis}

The next logical step after the qualitative analysis which resulted in the construction of the CMEP-matrix was the quantifying process of the collected data to be entered into the CMEP-matrix as numerical values of each CTV. When quantifying the qualitative results, the numerical values of each CTV-value were calculated by classifying the number of posi- tive/neutral/negative perceptions. The source data came from the SCA-research. (Sormunen, Eskelinen, 2010) The presentation can be developed in a more illustrative manner by con- structing a surface model from these numerical values. This is performed by changing the numerical values of the matrix into the height values of the surface model. As an essential part of this quantitative analysis, formulated Bézier surfaces were used as resulting surfaces,

SORMUNEN, Jari, ESKELINEN, Harri: Tools for Analysing Military Tactics...

which indicate the success of the tactical solutions and performance of an attack. In addition to the formulation of the surface, a specialized surface ratio curve is calculated to be able to evaluate the attacks by using quantified grading.

Based on the qualitative viewpoint, we already know how the columns of the CMEP-ma- trix describe "what is done" (lead, move, affect, maintain) and how the rows of the CMEP- matrix describe "in what ways these actions are carried out" (consciously, actively, simply, concentrated, continuously) when a company carries out an attack. When we integrate the third dimension with the matrix (z-axis), it is possible to evaluate from the viewpoint of tactics the success of exerh action and the success of an attack. This principle is illustrated in FigA XRMS (12) 2 (2013)

If we regard the numerical value of each central tactical variable as its assessment related to the success of the corresponding action described with this variable, the surface model constructed based on the numerical values of each CTV can be regarded as an overall as- sessment of the analyzed attack. The height values evaluate "how well" knowledge of the adversary and one's own force, activity, simplicity, concentration of effect and reserve and exertion of it have been carried out in relation with command and control, manoeuvre, effect and performance maintenance. The height values of the surface model change depending on time, which makes it possible to study the tactical phenomena at different moments during the progress of an attack or after the end of an attack. 


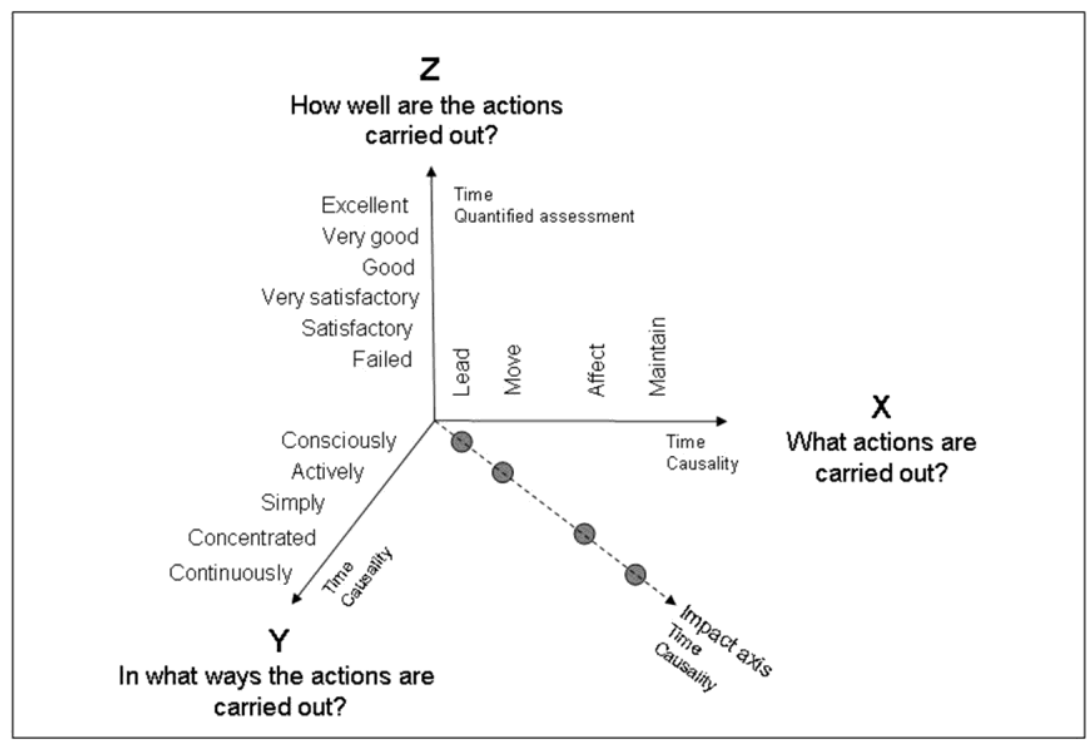

Figure 7. Integrating the z-axis with the CMEP-matrix.

The quantitative evaluations of task fulfilment and casualty data were integrated into the presentation by positioning the surface at the $\mathrm{z}$-axis according to the given numerical values of task fulfilment and casualty data. In the same way, it would be possible e.g. to change the positioning of the surface depending on the difficulty level of the task. This quantifying pro- cess is presented in outline in Fig. 8.

SORMUNEN, Jari, ESKELINEN, Harri: Tools for Analysing Military Tactics...

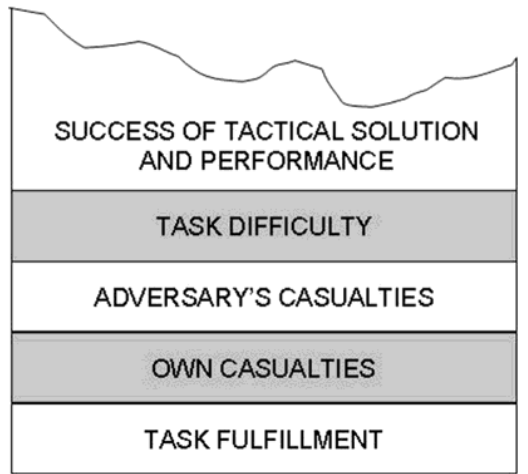

Figure 8. Quantifying process.

As shown in Fig. 8, the basic height values of the surface are calculated by summing up the scaled numerical values describing the task fulfilment and casualties. These values can be regarded as basic assessment criteria of success in the battle and therefore their scaled values are added to each central tactical variable to move the surface to the higher or lower level, which indicates how well the task is fulfilled and what the casualty ratio was after the battle. The additional quantified and scaled values of each central tactical variable are summed with these basic values. The stages of setting the height values on the surface are presented schematically in Fig. 9. 


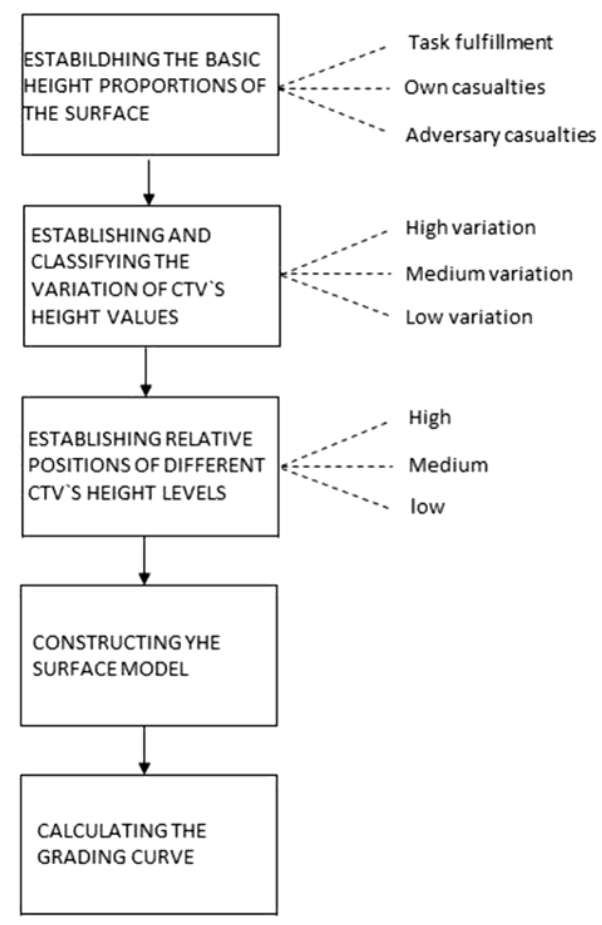

Figure 9.

The stages of setting the height values on the surface

SORMUNEN, Jari, ESKELINEN, Harri: Tools for Analysing Military Tactics...

The basic height values of the surface are calculated by summing up the scaled numerical values describing the task fulfilment (symbol H1) and casualties (own, symbol H2 and adver- sary, and symbol H3). These values can be regarded as basic assessment criteria of success in the battle and therefore their scaled values are added to each central tactical variable to move the surface to the higher or lower level, which indicates how well the task is fulfilled and what the casualty ratio was after the battle. The additional quantified and scaled values of each central tactical variable are summed up with these basic values. The scaling equations are as follows (comparing with Fig. 8):

- The basic height values Hbasic=H1+H2+H3 (scaled between $0 . .60 \mathrm{~mm}$ )

- Task fulfilment: $\mathrm{H} 1=0$ (task is failed) or $30 \mathrm{~mm}$ (task is fulfilled)

- Own casualties: $\mathrm{H} 2=((100$-own casualties $\%) / 100) \times 15 \mathrm{~mm}$

- Adversary's casualties: H3= (adversary's casualties \%/100) $\times 15 \mathrm{~mm}$.

When setting the hypothesis, the assumed height values of the additional height portion of the surface models for tactical interpretation are established by utilizing mathematical conditions which describe the relative differences of importance between the central tactical variables. In addition to these conditions, the maximum and minimum values (variation) are set for each central tactical variable and the final estimation is made by utilizing the median.

An example of the Bézier surface, which is calculated based on the measured data in the SCA-research (Sormunen, Eskelinen, 2010), for successful attacks is presented in Fig. 10.

190

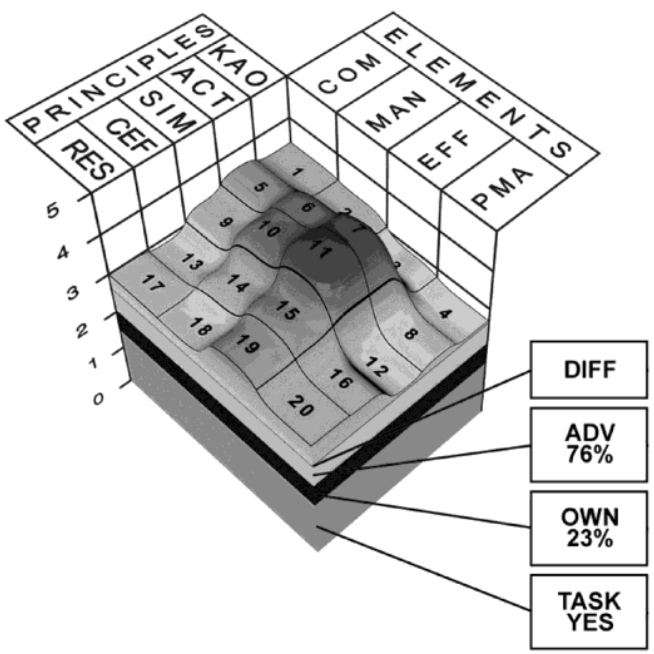

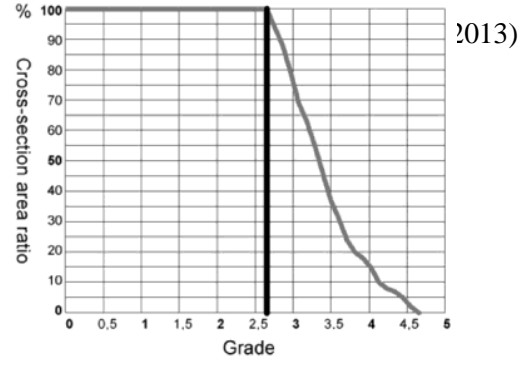

Figure 10. Calculated Bézier surface and the grading curve. 


\section{Calculating the Surface Area Ratio Curve}

From the produced surface model of the CMEP-method, it is possible to cut different slic- es along the $\mathrm{xy}$, yz or $\mathrm{zx}$ planes to evaluate different tactical aspects or to conduct a time dependent analysis of them. The calculated grading curve (surface area ratio curve) of the

SORMUNEN, Jari, ESKELINEN, Harri: Tools for Analysing Military Tactics...

CMEP-method makes it possible to carry out an exhaustive and overall evaluation of the attack exercise. To be able to evaluate the tactics of the battles by using quantified grading, the surface area ratio curve is calculated. An example is presented in Fig. 11.

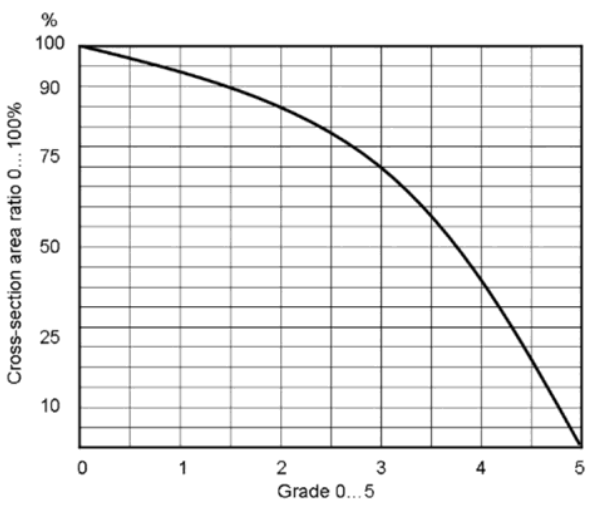

Figure 11. The surface area ratio curve.

From this curve, it is possible to read how large a relative portion of the CTVs have reached the required grading level. On the other hand, it is possible to set a grading value which divides the battles into successful or unsuccessful ones. This curve also shows how wide the basis for success has been or if only a few CTVs affecting success have reached the required level. This grading curve is an application of the Abbott-Firestone curve, which is applied to surface analysis (Schmahling, Hamprecht, 2007: 11-12, 262, 1360-1371).

\section{Bézier Surface Modeling to Support Tactical Analysis}

Results of the recent Human Factors Conferences have discussed the importance of visuali- sation in describing the phenomena in the battle space for years. According to these results, exocentric 3D applications proved to be more powerful compared to immersive ones. In analogy to this, the surface presentation of the CMEP-method is constructed to help the user more easily form an overall tactical understanding of the analyzed results.

Bézier surfaces are an extension of the idea of Bézier curves and share many of their properties. In the same way as the Bézier curve uses the more tractable control polygon in place of control points and tangent vectors, the Bézier surface formulation uses a character- istic mesh in place of points and tangent and twist vectors. In an analogical way with Bézier curves, Bézier surfaces pass through the corner points of the characteristic polygon only and they have edge curves that are tangential to the edges of the characteristic polygon at the cor- ner points. These surfaces are variation diminishing and have a convex hull property.

These properties of Bézier curves show that they have a number of limitations of the re- lated curves. They only allow global modification and are somewhat constraining if a smooth transition between adjacent patches is to be achieved.

However, although the limitations of Bézier curves in exact surface modelling are known, it is noticeable that in this mesangh, (the zoritions of control points are set in the middle of

191

SORMUNEN, Jari, ESKELINEN, Harri: Tools for Analysing Military Tactics..

each CTV and the curves for surface modelling are allowed to follow the path of Bézier curves between the adjacent points. This modelling technique allows for illustration of the researched phenomena with a surface model with a relatively simple and quick data entering interface. Nevertheless, it makes it possible to analyze the properties of the surface with mathematical means if needed: the equation of the points on a Bézier surface is given in (McMahon, Browne, 1998).

The leading thought when designing the use of quantitative tools has been simplicity, es- pecially when presenting the final results of the analysis of tactical solution and performance. However, the usability and feasibility of the developed method can be improved through mathematics. In this research, it means at first that an easy-to-understand data format is used to enter material into CAD-software. Secondly, this computer-aided tool produces, without any practical 
modelling work, illustrative figures to present sometimes highly complicated phenomena relevant to tactics.

Bézier surface presentations are utilized both to support decision-making and to integrate the results of several design or reasoning stages, e.g. in optimum shape design. Vucina et al.,

2012: 3, 4, 25, 201-207) Also other possibilities to utilize Bézier curves in different types of practical applications have been evaluated (Sohel et al., 2008) to improve the local informa- tion gained from the surface model. Different types of enhanced Bézier curve models have been presented in literature (Sohel et al., 2007). Extensive research has also been conducted to find means to describe the shape information of Bézier surfaces for interpreting different modelled phenomena. (Sohel et al., 2007) These aspects are of great interest when there is a need to integrate qualitative and quantitative measurement results to support tactical analysis.

When evaluating the reliability aspects of the surface modelling, two main points were checked: how the selected Bézier surface calculation differed from other possible modelling techniques in relation to pattern recognition and what the difference was in grading.

The point of interest is the higher levels of the surface, which start above the layers de- scribing one's own and the adversary's casualties together with task fulfilment. Four different surface modelling techniques were compared: Bézier, Mozaic, Pyramid and Block surfaces. Basically, the Mozaic-model describes exactly the measured values of each item in all twen- ty CTVs. Compared to this, the Block model summarizes the values of different items within each of the twenty CTVs and it shows the summarized values of each CTV correctly. The Pyramid model is otherwise the same, but only the peaks are illustrated with the sharp vertex of twenty cones.

The idea of the CMEP-method is to combine the time aspect into both CMEP-matrix axes, which means that the heights of the neighbouring bars should change smoothly accord- ing to the tactical phenomena. Unlike the other modelling techniques, the Bézier surface is able to illustrate this feature due to its mathematical properties. The comparison results of dif- ferent grading curves and the surfaces of each modelling technique are presented in Fig. 12.

SORMUNEN, Jari, ESKELINEN, Harri: Tools for Analysing Military Tactics...
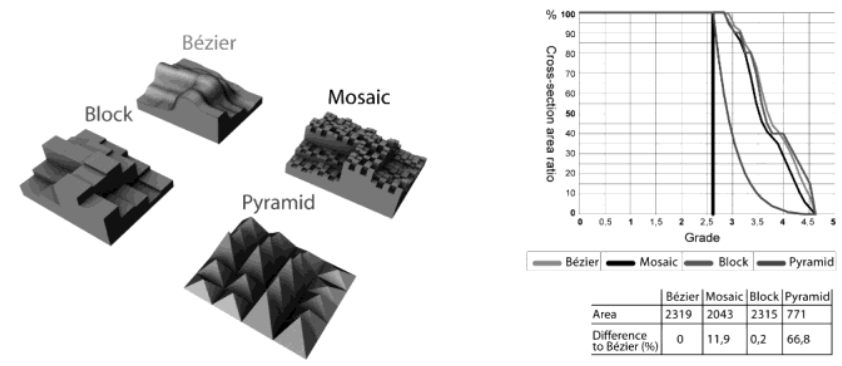

Figure 12. Comparison of different surface modelling techniques.

The comparison of the grading curves shows that on an average, the quality of grading in the Bézier model is $11.9 \%$ higher than in the Mosaic-model. On the other hand, the grading curve of the Mosaic model suffers from an unnatural stepwise progress of the curve. It is interesting to notice that the difference between the grading curves of the Bézier and Block models is only $0.2 \%$.

\section{Interpretation of Bézier Surface Patterns to Analyze Tactics}

As a part of advances in computing in military operations research (OR), especially in tac- tical decision-making, the surface interpretation is based on recognizing some geometrical shapes from the surface pattern. This recognition process is supported by a picture series describing the most relevant surface shapes which are assumed to present some tactical phe- nomena and their success.

The calculated Bézier surface is compared with theoretical surfaces based on which a set of definition maps were produced to support the interpretation process of military tactics. The comparison is divided into the following three parts:

- Geometric similarity of the definition maps and the calculated surface pattern

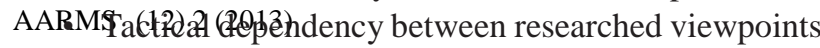

193

- Synthesis of the surface patterns

From the top view of the calculated surface, it can be proved that surface patterns at dif- ferent height levels of the surface indicate and highlight, by different weightings, the aspects which have an effect on the result of the battle. It is as important to recognize these surface patterns at different height levels as it is to recognize the surface pattern at the highest (most visible) surface level. This shows that several aspects simultaneously have an effect on the result of the battle. It also demonstrates that depending on the battle situation, the impact factor of these aspects varies. As documented in Table 3, in this case example, only one chain is named and analyzed. In this case, according to tactical interpretation, in order to enable ini- tiative in battle, the leaders have ensured the freedom of action by maintaining the possibility to affect in creative ways and by avoiding force binding. In addition to this, the leaders have been open to looking for new possibilities and to taking initiative. Initiative in manoeuvres, effects and other actions has shown in proactive actions to vary situations and the unexpected actions of the adversary. The leaders have had a strong 
understanding of utilizing the unit's and its subunits' execution capability and they have understood the necessary functions to

SORMUNEN, Jari, ESKELINEN, Harri: Tools for Analysing Military Tactics..

carry out the planned, prepared and trained actions before the adversary has time to force them to do so. Both the leaders and the subunits have had the courage and the justification to find and use the effects of supporting branches in a simple and creative way to fulfil the battle task.

Table 3. Surface pattern recognition and interpretation process.

\begin{tabular}{|l|l|l|l|}
\hline $\begin{array}{l}\text { Constructed surface and } \\
\text { its top view and recog- } \\
\text { nized pattern shape }\end{array}$ \\
\end{tabular}

\section{Discussion and Conclusions}

The aim of the CMEP-method is to integrate several different variables and affecting factors into one overall tactical analysis according to the leaders' decisions, solutions, and orders and according to the unit's actions and according to the events in the battle space.

By integrating a qualitative and quantitative analysis of an attack within the Bézier sur- face model, it is possible to extract and identify certain key points of the battle:

- Was the battle task fulfilled and the battle victorious?

- At what cost was the outcome of the battle achieved?

- Is the timing correct, related to the tactical solutions and selected actions during the battle?

- Were the decisions and actions actively justified?

- What were the key variables and culmination points of the attack?

Because the surfaces are produced from measured data into the form of Bézier surfaces, it is possible to add mathematical comparison and pattern recognition to the CMEP-method.

The primary challenge was in finding an appropriate way to handle several qualitative parameters describing tactical aspects. The sensitivity analysis of the CMEP-method con- sists of interaction between three main analysing stages, which are 1) the accuracy of the measured data, 2) the mathematical sensitivity of the CMEP-method and 3) the sensitivity

SORMUNEN, Jari, ESKELINEN, Harri: Tools for Analysing Military Tactics...

194

AARMS (12) 2 (2013)

of the CMEP-method's definition maps to support relevant interpretations dealing with the analyzed tactical phenomenon. The sensitivity analysis of the CMEP-method shows that it is possible to affect the resolution of the surface model by tuning the scaling of different layers of the surface model. However, a sufficient amount of source data is more critical to ensure that the height differences of the surface model are clear enough to illustrate different tactical aspects.

\section{References}

BELLAMY, C. (1990): The Evolution of Modern Land Warfare, Theory and Practice.

Routledge Field Manual, The Finnish Defence Forces (1984): Jaeger Brigade's Battle Guideline (PR TST-OHJE 1984), Gummerus

Field Manual, The Finnish Defence Forces (2008): Infantry Company's Battle Guideline (KOTO 
2008). Edita Prima Oy

LIDDELL, B. H. (1954): Strategy - the indirect approach. New York: Frederick Praeger, Inc. LIND, W. (1985):

Manoeuvre Warfare Handbook. Westview Special Studies in Military Affairs McMAHON, C., BROWNE, J. (1998):

CADCAM principles, practice and manufacturing management. 2nd Edition, Addison Wesley Longman

MILES, M., HUBERMAN, M. (1994): Qualitative Data Analysis. 2nd Edition, Thousand Oaks

SCHMAHLING, J., HAMPRECHT, F. (2007): Generalizing the Abbott-Firestone curve by two new surface descriptors. Wear https://doi.org/10.1016/j.wear.2007.01.025

SOHEL, F., KARMAKAR, G., DOOLEY, L., ARKINSTALL, J. (2007): Bezier curve-based character descriptor considering shape information. In. 6th IEEE/ACIS International Conference on Computer and Information Science

SOHEL, F., KARMAKAR, G., DOOLEY, L., ARKINSTALL, J. (2008): Enhanced Bezier curve models incorporating local information. In. IEEE International Conference on Acoustics, Speech, and Signal Processing

SORMUNEN, J., ESKELINEN H. (2010): Measured Tactics - Success Factors of Infantry Company's Attack. Edita Prima Oy

VUCINA, D., LOZINA Z., PEHNEC, I. (2012): Computational procedure for optimum shape design based on chained Bézier surfaces parameterization. Engineering Applications of Artificial Intelligence 